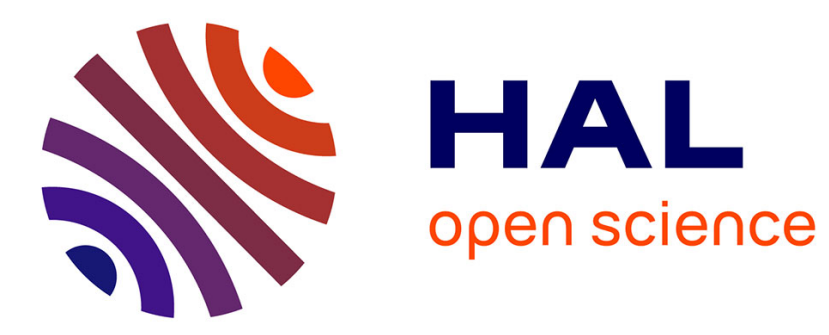

\title{
Quick GPS: A new CAT system for single-part tolerancing
}

Bernard Anselmetti, Robin Chavanne, Jian-Xin Yang, Nabil Anwer

\section{To cite this version:}

Bernard Anselmetti, Robin Chavanne, Jian-Xin Yang, Nabil Anwer. Quick GPS: A new CAT system for single-part tolerancing. Computer Aided Geometric Design, 2010, 10.1016/j.cad.2010.04.006 . hal-01239222

\section{HAL Id: hal-01239222 \\ https://hal.science/hal-01239222}

Submitted on 11 Dec 2015

HAL is a multi-disciplinary open access archive for the deposit and dissemination of scientific research documents, whether they are published or not. The documents may come from teaching and research institutions in France or abroad, or from public or private research centers.
L'archive ouverte pluridisciplinaire HAL, est destinée au dépôt et à la diffusion de documents scientifiques de niveau recherche, publiés ou non, émanant des établissements d'enseignement et de recherche français ou étrangers, des laboratoires publics ou privés. 


\title{
QUICK GPS: A new CAT system for single part tolerancing
}

\author{
Bernard Anselmetti a,b,_, Robin Chavannea,b, Jian-Xin Yanga,c, Nabil Anwera,d
}

a LURPA, ENS Cachan, 61, Avenue du Président Wilson, 94235 Cachan Cedex, France

IUT Cachan, Université Paris-Sud 11,9, avenue de la division Leclerc, 94230 Cachan, France

c Beijing University of Technology, 100124 Beijing, China

d IUT St. Denis, Université Paris 13, Place du 8 Mai 1945, 93205 Saint-Denis, France

Computer-Aided Design 42 (2010) 768_780

\section{Abstract:}

This paper depicts a new CAT (Computer Aided Tolerancing) system called Quick GPS (Geometrical Product Specification), for assisting the designer when specifying the functional tolerances of a single part included in a mechanism, without any required complex function analysis.

The mechanism assembly is first described through positioning table formalism. In order to create datum reference frames and to respect assembly requirements, an ISO-based 3D tolerancing scheme is then proposed thanks to a set of rules based on geometric patterns and TTRS (Technologically and Topologically Related Surfaces). Since it remains impossible to determine tolerance chains automatically, the designer must impose links between the frames. The CAT system we developed here proposes ISO based tolerance specifications to help ensure compliance with the designer's intentions saving on time and eliminating errors.

This paper will detail both the set of tolerancing rules and the designer's approach. The Quick GPS system has been developed in a CATIA V5 environment using CATIA VBA and CATIA CAA procedures.

\section{Keywords:}

ISO tolerancing standards, Functional Dimensioning and Tolerancing, CAT systems, specification synthesis, tolerancing rules, positioning table.

\section{INTRODUCTION}

The tolerancing data reported by the designer on technical drawings are becoming nowadays very critical when formalizing the contractual relationships between companies. In industry, functional tolerancing of mechanisms is today more and more based on ISO GPS (Geometrical Product Specification) and ASME Y14.5-2009 standards. The designer's activity consists also on optimizing parts so as to increase mechanism quality while reducing costs.

This tolerancing activity requires time, a good knowledge of standards and the use of CAD systems (Computer Aided Design), while the designer must have expertise and skills for selecting appropriate tolerancing specifications.

Within a classical approach towards tolerancing, the designer determines the geometrical functional requirements of the mechanism according to function analysis. For each requirement, the designer must identify the influent parts and the 3D tolerance chain, choose tolerances and verify all the results of tolerance chains computation.

Current industrial CAD software's do not have specific tolerancing workbenches that cover all the above tasks and only few research works allow quick functional dimensioning and tolerancing based on ISO GPS concepts [1, 2 , 3] and tolerance editing controlled by syntactic analysis [4].

FT\&A (Functional Tolerancing and Annotation) workbench of CATIA V5 (Dassault Systèmes) [5] uses a specific GD\&T (Geometric Dimensioning and Tolerancing) editor and enables syntactic analysis. FT\&A is based on TTRS (Technologically and Topologically Related Surfaces) approach [6]. The designer must select datum reference frame and toleranced surface. A dialog box proposes only acceptable specifications and modifiers.

Several CAT systems are dedicated to tolerance analysis such as $3 D_{C S}{ }^{\circledR}$ (Dimensional Control Systems), $\mathrm{CETOL}^{\circledR}$ (Sigmetrix), VSA ${ }^{\circledR}$ an eM-TolMAte (Siemens PLM). Assembly of parts is simulated (Monte Carlo simulation approach) considering the geometrical defects limited by the chosen tolerances. In Tolerance Manager $^{\circledR}$ (PCO technologie), the designer must define the set of tolerance chains and the tolerance values. A dashboard presents the results of tolerance chains with worse case or statistical approach. In Mecamaster [7], the designer creates an isostatic model of the assembly and the system determines the influence of each part deviation on one requirement.

SolidWorks DimXpert [8] is used to tolerance a part using either automatic or manual mode based on GD\&T Symbols and according to ISO 1101 and ISO 16792 and also ASME Y14.41-2003 standards. Under-constrained, iso-constrained and over-constrained conditions of a part are considered and highlighted by a set of colors. DimXpert GD\&T layout forms the basis for Tolerance Analysis using SolidWorks TolAnalyst module.

The modular system FROOM (Features and Relations used in Object Oriented Modeling) developed by Salomons and al is based on $\mathrm{ACIS}^{\circledR}$ kernel modeller environment. The first module generates geometrical specifications with TTRS approach [9]. Designer chooses tolerances. The second module performs tolerance analysis 
with torsor concept [10]. The resulting specifications are very basic and didn't cover for example common zones and modifiers.

In order to provide the designers with complete and reliable solutions, the CLIC system (French acronym for "Cotation en Localisation avec Influence des Contacts") developed by Anselmetti [11, 12, 13] proposes the automatic generating of functional requirements, functional specifications in accordance with ISO tolerancing standards and 3D tolerance chains considering worst case and statistical approaches [14] (Fig. 1).

Today, CLIC system has been applied successfully and can process simple mechanisms while producing detailed tolerancing data in a short time (10 minutes for a 5 parts mechanism and 100 generated specifications).
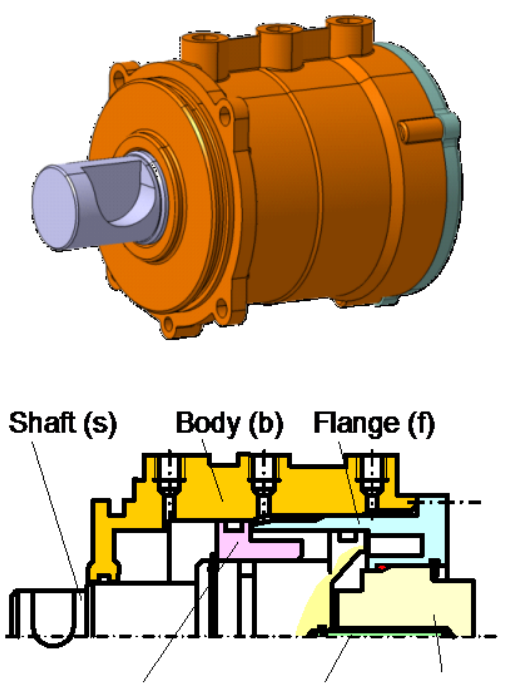

Piston (p) Probe finger (pf) Spool (sp)

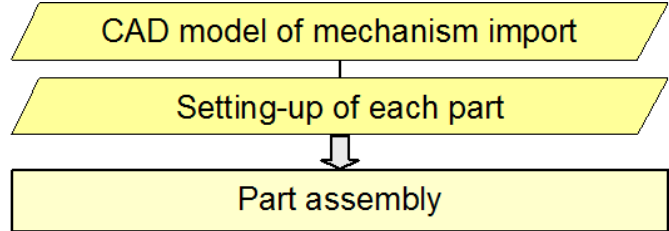

Generation of requirements, definition of other requirements

Tolerancing of influential parts

Result of tolerance chains

Variation of CAD nominal models

Optimization of tolerances

DL

Functional specifications

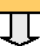

Variations of nominal models

Figure1: Tolerancing in CLIC

When considering complex mechanisms with many parts, the overall design process involves many designers and each of them is responsible for single part tolerancing. The Quick GPS method proposed here, that conforms to ISO GPS Tolerancing standards, is a new approach for tolerancing single parts that ensure consistent tolerancing for the entire mechanism (Fig. 2). This method requires information sharing among the designers and due to its simplicity it is intended to achieve only limited objectives. Quick GPS can also be considered as the first stage of CLIC system, without tolerance chains.

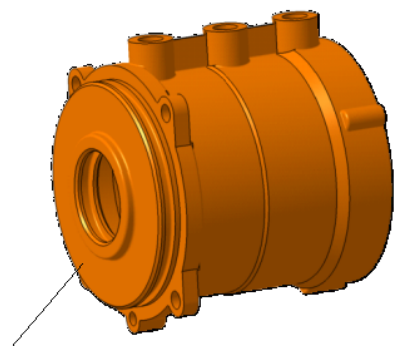

Body (b)

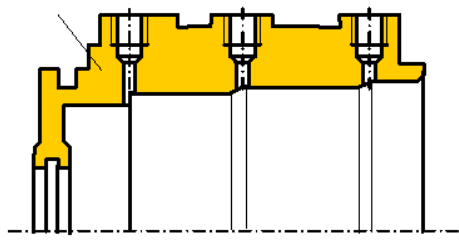

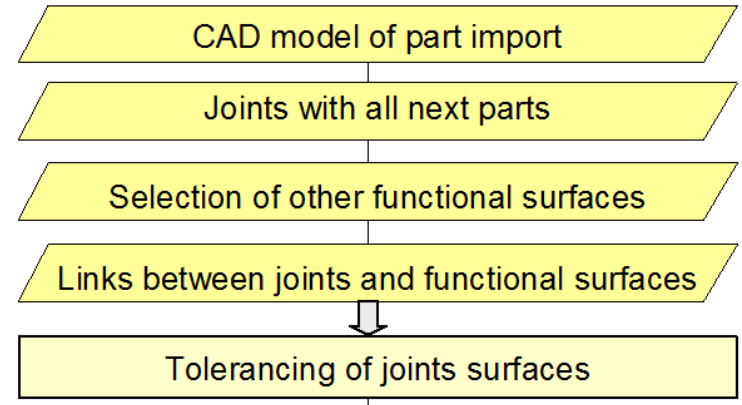

Tolerancing between joints

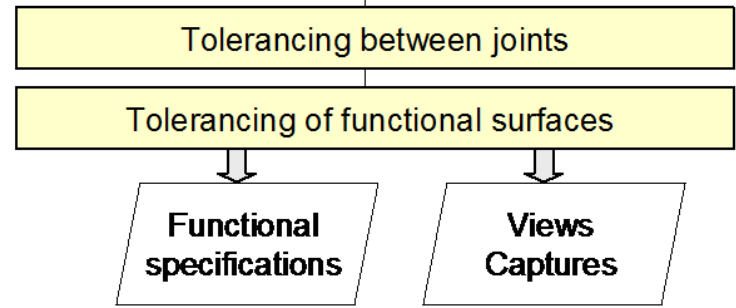

Figure 2: Tolerancing in Quick GPS 
In the following sections, we will focus on specification synthesis of a single part, in accordance with the ISO GPS standards. In Section 2, a case study mechanism will be described, while Section 3 will develop the tolerancing rules for specifying all contact surfaces based on positioning requirements. Section 4 will then describe an alternative method for the classical 3D chain transfer. Section 5 will illustrate an application of the Quick GPS system in a CATIA V5 CAD environment using both VBA and CAA procedures.

\section{MECHANISM DEFINITION}

\subsection{The studied mechanism}

The Quick GPS method will be illustrated in this paper through a case study: "air control of a gearbox" (Fig. 3), the approach can be used for all mechanisms consisting of rigid parts without loss of generality. The shaft has three positions for moving an arm connected to the gearbox that modify the air input.

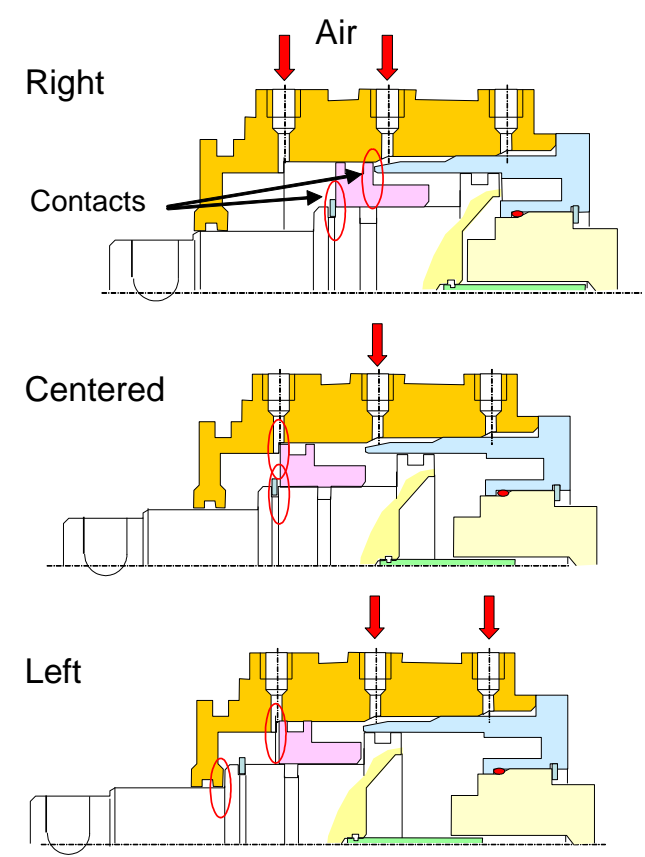

Figure 3: Three configurations of the mechanism

To ensure consistent tolerancing, the designers must define the positioning plan.

\subsection{The positioning graph}

Tolerancing a mechanism depends on its part positioning. For each configuration of the mechanism, the set-up of the parts is represented by one positioning graph (Fig. 4). The most left part of the graph is called a "base". One after another, each part on the right is positioned on the part located to its left on the graph. It is also possible to assemble a subset, called a "block", along with its proper base. A block is composed of parts without mobility.

Figure 4 presents the positioning graph in the left configuration. The body is the base of the body block. The flange is setting-up in the body. The spool is fixed in the flange. The shaft is centered in the body block and is in contact with the body. The piston is centered on the shaft and is in contact with the body. The probe finger is setup by the shaft and the spool. Whereas in the centered and right control configurations, the piston is blocked on the shaft and this shaft block move between these two configurations. 


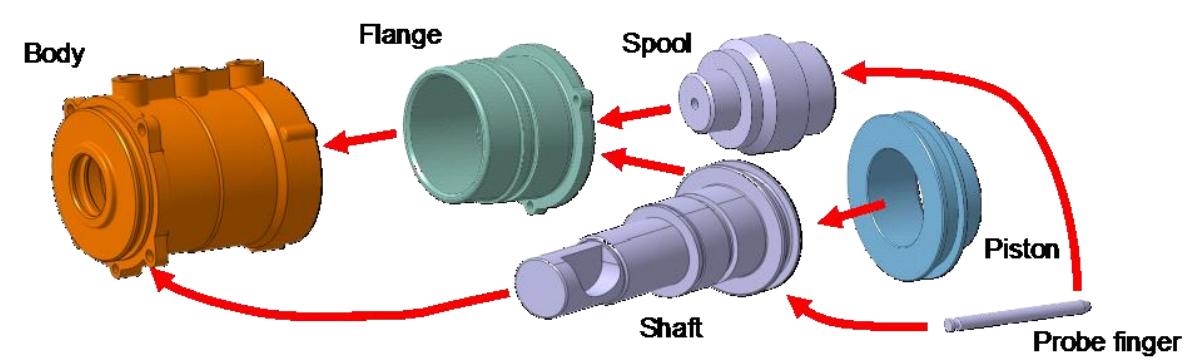

Left Configuration

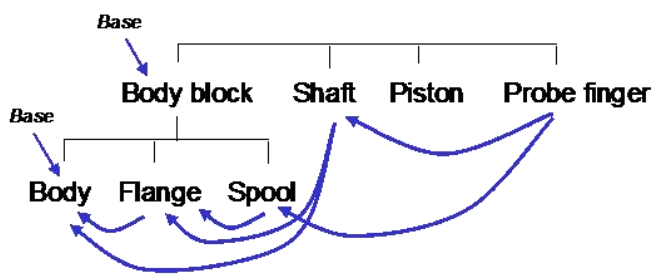

Centered and right Configurations

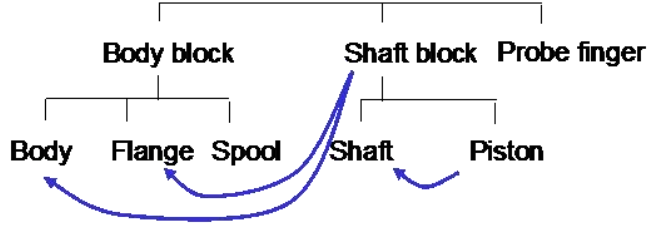

Figure 4: Two positioning graphs for the three configurations

\subsection{The positioning tables}

The positioning of each part (and each block) on positioning graph (except for the bases) must be described using a positioning table. For this purpose, designers must consider degrees of freedom blocked by each positioning feature. The feature that removes the maximum of the degrees of freedom in orientation is the primary feature. The secondary and tertiary features must then impose at least one degree of freedom [12,15].

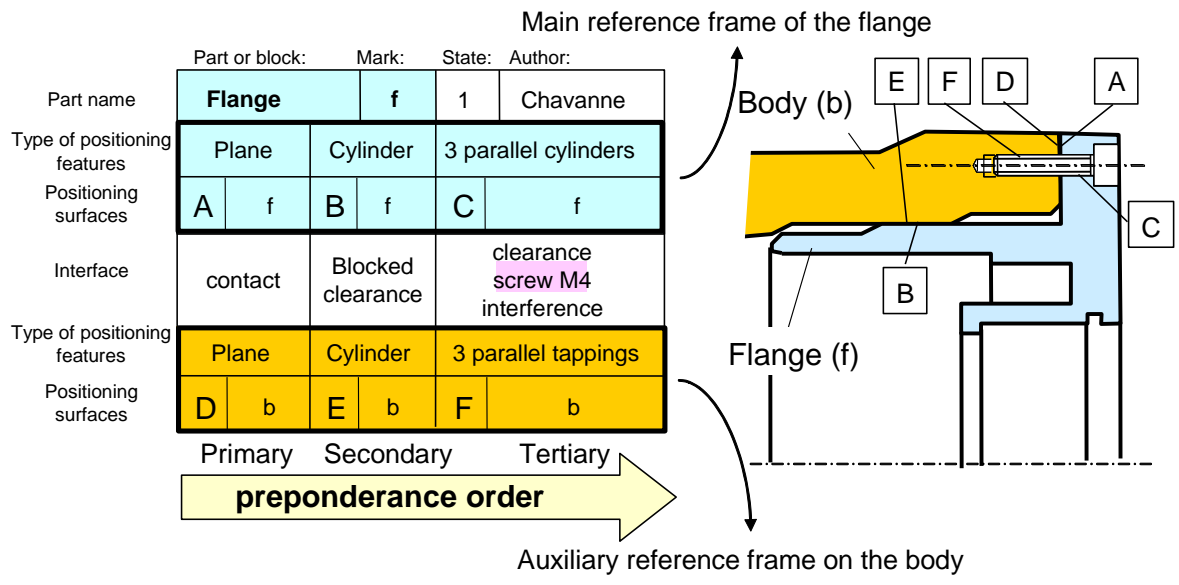

Figure 5: Positioning table of the flange

The positioning table (Fig. 5) describes the flange setting up. The Plane A of the flange is in contact with the plane $\mathrm{D}$ of the body in order to define the primary feature. The Cylinder $\mathrm{B}$ of the flange is centered in the cylinder $\mathrm{E}$ of the body, with clearance to constitute the secondary feature. The Set C containing three holes of the flange is in front of the set $\mathrm{F}$ of three tappings of the body. Three screws fitted in the tappings locate the flange with clearance.

Basic positioning surfaces are either a cylinder or a plane, yet very often a set of surfaces constitutes a composite positioning feature as well as a group of parallel cylinders. The three classical interfaces are the contact, the clearance, and the interference.

During this step, designers take into account the parts defects and forces applied to the part before making key decisions regarding product quality and potential failure in the case of surface deviations. In Figure 5, plane $D$ locates and orientates the flange. This orientation cannot be performed by cylinder $E$ because the common length of both the body and flange cylinders is very short and moreover a clearance lies between these two parts. D therefore is a primary surface. In addition, this approach serves to verify compliance of the positioning face dimensions with respect to the preponderance order.

The third row of the table defines the main datum reference frame $A|B| C$ of the flange, according to the datum reference frame definition found in ISO tolerancing standards. The last row depicts the auxiliary datum reference frame $D|E| F$ to be created on the body in relation to the flange. 
The positioning tables are defined for each part and are made available to each designer. With this common database, team of designers can work independently but generate a consistent and robust tolerancing of the mechanism.

The assembly or specification tree currently used in CAD systems cannot provide the same data. For example, designer can center any cylinder of the flange on any cylinder of the body. There is no precedence order between plane and cylinder and no information on the clearance or interference between parts.

Other approaches group all data in one complex graph (nodes represent the parts, and edges represent the links between surfaces of the parts). M. Linares [16] defined functional positioning features in the node. In their work, A. Ballu, L. Mathieu [17] and D. Tessandier [18] added the type of kinematic joint as an attribute to the edge (e.g. planar joint, revolute joint). M. Samper [19] noted the type of contact on the edge (e.g. fixed, sliding, floating, forbidden), whereas B. Marguet oriented edges from the base to their end parts [20].

\subsection{Positioning features recognition}

A CATIA V5 based interactive procedure has been developed to define the positioning surfaces of the body. In a three-step sequence (Fig. 6), the designer selects the set of primary, secondary and tertiary surfaces. A dialogue box enables the designer to detail the interface between the various positioning surfaces (contact, clearance, interference, etc.). With the current VBA procedure, it is not possible to detect the thread on a hole. This dialogue box serves also to define tapping as an interface for the set of threads.

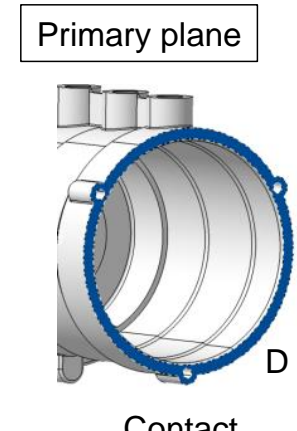

Contact

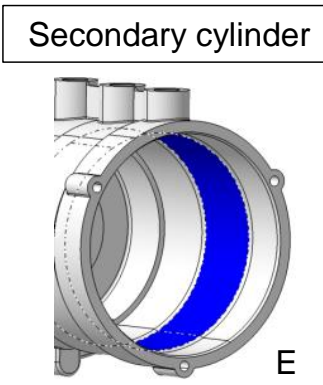

Clearance

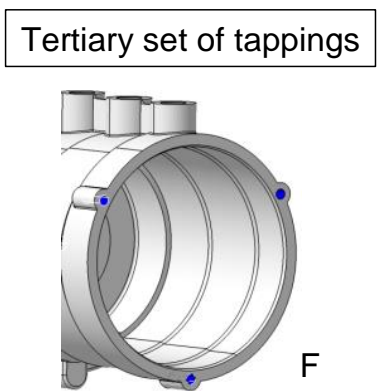

Tappings

Figure 6: Selection of positioning features of the flange

This interactive selection is straightforward; nonetheless, Armillotta [21] proposed a method for automatically recognizing these contact surfaces on the CAD assembly model. The precedence order is based on surface area.

For each selection, CATIA VBA procedures recognize the elementary geometry features: plane, cylinder, sphere, cone, torus (Fig. 7). Geometric characteristics can then be extracted from this recognition phase (point, vector, radius, etc.).

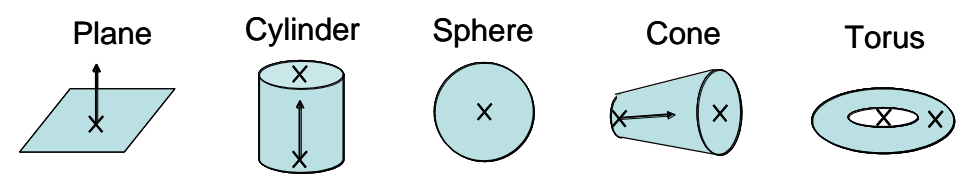

Figure 7: Elementary surfaces identified from the CAD model

If the positioning feature is composed of several elementary surfaces, then the combinations between geometric characteristics would enable determining the type of feature that allows differentiating coaxial cylinders from, for example, a set of parallel cylinders. Moreover, each positioning feature is associated with a TTRS class, so as to apply the set of rules listed above. Figure 8 indicates the set of available positioning features in the current version of Quick GPS. 


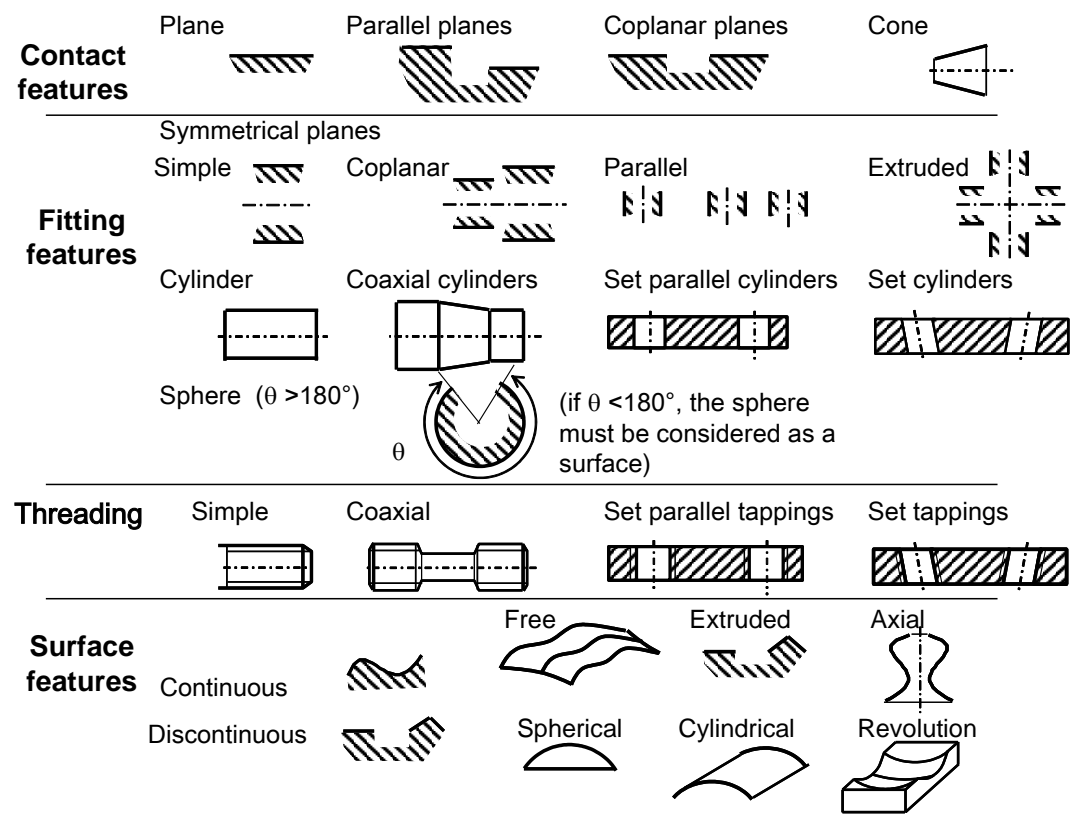

Figure 8: List of positioning features

\subsection{Set-up verification}

During each step, a set of rules serve to verify junction consistency. The first rule is based on TTRS theory and ensures that each datum reference frame created is indeed consistent. The primary feature must define one of the six classes (plane, cylinder, revolute, prismatic, spherical and complete). Any reclassification of the primary and secondary features must result in a class different from the primary class.

Figure 9 shows an example with primary cylinder A and secondary plane B. This case is well accepted by TTRS theory and the syntax control on the CATIA FTA workbench. The Quick GPS procedure takes into account the size of surfaces and detects that the length of the cylinder is very small with respect to its diameter. If ever Length $<0.5 \times$ diameter, a warning is displayed.

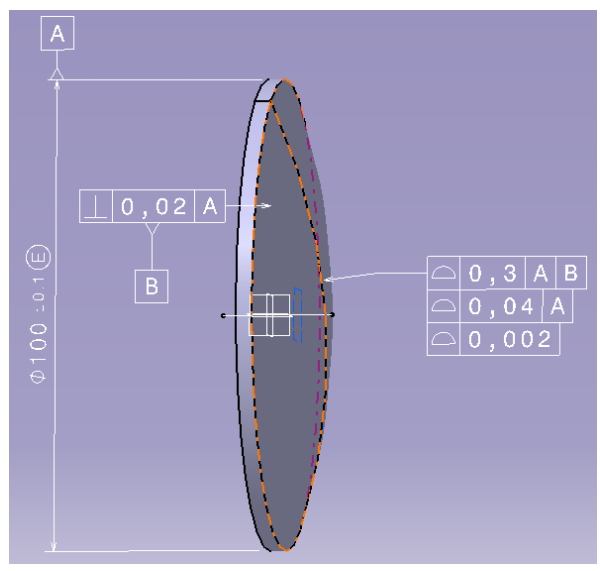

Figure 9: Part set-up verification

\subsection{Other functional surfaces}

To complete the mechanism definition, the designer must select other isolated functional surfaces from CATIA part model (e.g. surface 13b corresponding to the piston external cylinder, and plane 14b in contact with the face of the piston face and set of fixture holes 22,23,24 and 25b) (Figure 19).

\section{DATUM SYSTEM SPECIFICATIONS}

\subsection{Positioning requirements}

Part tolerancing can now be established. These specifications must ensure both part assembly and contact quality (Fig. 10).

- Primary surfaces in contact need specifying the form of surfaces in order to control the maximum distance between surfaces lying in contact. 
- Secondary or tertiary surfaces in contact impose an orientation specification with respect to the primary reference.

- Clearance or interference of a primary cylindrical joint imposes part diameters and the envelop requirement.

- Clearance of a secondary or tertiary cylindrical joint necessitates to control the maximum material boundary.

Primary joint

a) Maximal distance between surfaces in contact

$$
\begin{array}{|l|l|}
\hline \square & \mathrm{t} 1 \mathrm{e} \\
\hline
\end{array}
$$

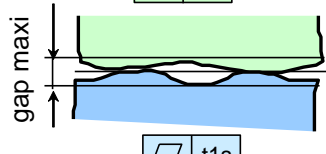

c) Clearance or interference

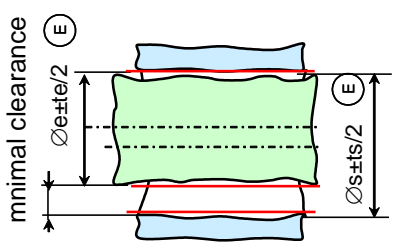

Secondary or tertiary joint

b) Maximal distance between surfaces in contact
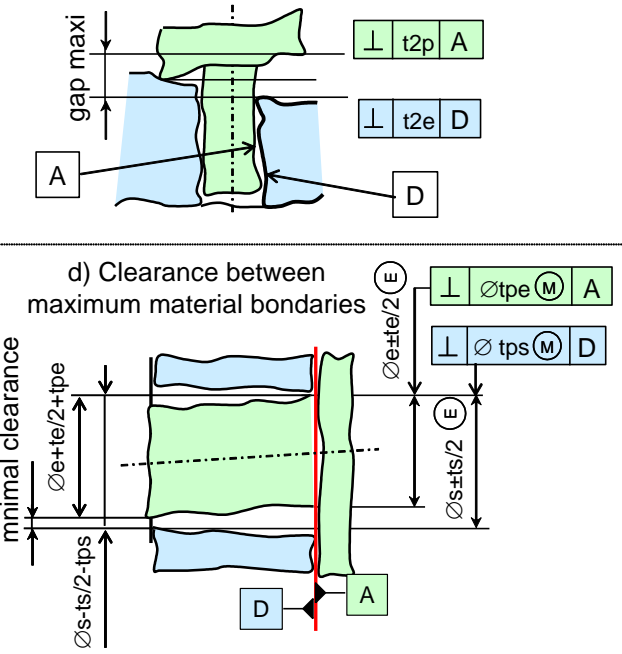

Figure 10: Positioning requirements and corresponding tolerancing

\subsection{Tolerancing of positioning features}

The functional specifications of the corresponding positioning requirements are depicted in patterns for each type of positioning feature and for the primary, the secondary and the tertiary cases as well (Fig. 11).

In these patterns, the perpendicularity symbol indicates orientation specification while the location symbol identifies the positioning specification, but this symbol must be in accordance with rule 2 (section 3.4).

\begin{tabular}{|c|c|c|c|c|c|}
\hline Primary feature & Secondary feature & Tertiary feature & Primary feature & Secondary feature & iture \\
\hline Plane $\quad \mathrm{A}_{\sqrt{ }} \mathrm{G} / \mathrm{t}$ & 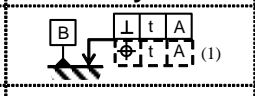 & 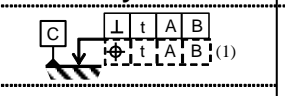 & $\begin{array}{l}\text { Symmetrical } \\
\text { parallel } \\
\text { planes }\end{array}$ & 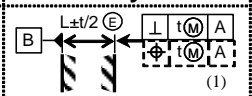 & 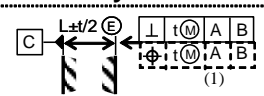 \\
\hline 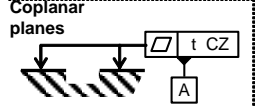 & 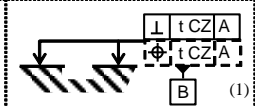 & 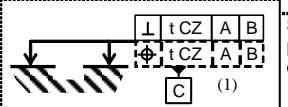 & $\begin{array}{l}\text { Symmetrical } \\
\text { planes } \\
\text { extruded }\end{array} \rightarrow$ & 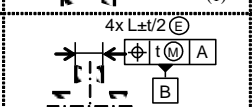 & 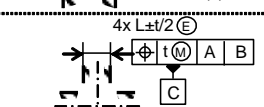 \\
\hline $\begin{array}{l}\text { Parallel } \\
\text { Planes }\end{array}$ & \begin{tabular}{|l|l|l|} 
& $t C Z$ & $A$ \\
\end{tabular} & N & & & \\
\hline$\left.\int_{A}^{v}\right|^{\downarrow}$ & ${ }^{v}=\mathbb{N}^{(2)}$ & 视 (1) & Cone $\frac{\sqrt{1}}{-\ldots . .}$ & & \begin{tabular}{|l|l|l|}
$t$ & $A$ & $B$ \\
T & $(2)$ \\
\end{tabular} \\
\hline cylinder & 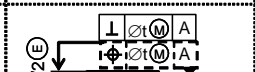 & 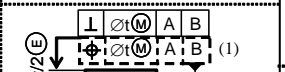 & & & \\
\hline A & 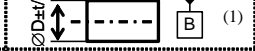 & 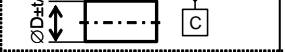 & Threading $\begin{array}{l}\text { M14 } \times 2,69-69 \\
\sqrt{ }\end{array}$ & 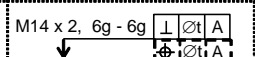 & 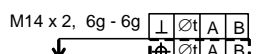 \\
\hline coaxial cylinders & 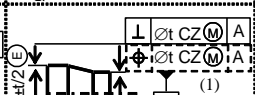 & 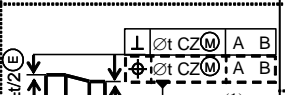 & $\begin{array}{l}\text { on } \\
\text { thread }\end{array}$ & 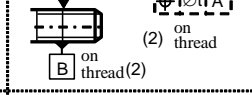 & 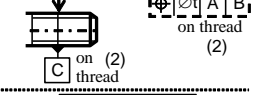 \\
\hline Q & 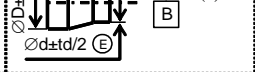 & 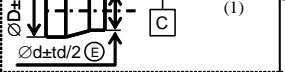 & Sphere & 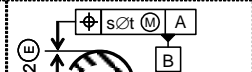 & 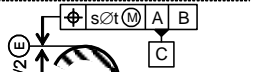 \\
\hline Set of cylinders $2 \times \varnothing \mathrm{d} \pm \mathrm{td} / 2(\mathrm{C})$ & 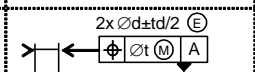 & $\psi \leftarrow$ & & & \\
\hline 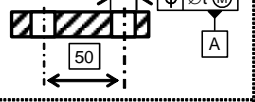 & $\underset{:}{\stackrel{500}{\longleftrightarrow}}$ & U:FZ10 & $\begin{array}{c}\text { Continuous } \\
\text { surface }\end{array}$ & Nit & $\leqslant \frac{1}{c}$ \\
\hline 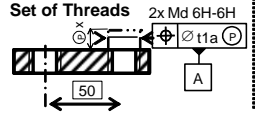 & 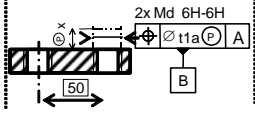 & 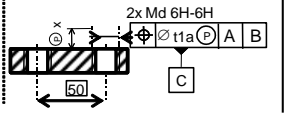 & $\begin{array}{l}\text { Discontinuous } \\
\text { surface }\end{array}$ & & \\
\hline
\end{tabular}

Figure 11: Patterns for positioning feature tolerancing

This tolerancing method is very efficient and can be easily used by the designer. Clement [22] and Salomons [9] have a similar approach using TTRS concept, but their table cannot distinguish features in such as simple planar, coplanar planes, parallel planes, and symmetrical planes. The specifications are then very basic and do not take into account clearance or interference in joint in order to add modifier in specifications. 


\subsection{Rule 1: Pattern selection}

The selection of positioning surfaces of the flange on the body (Fig. 6), the feature recognition and the definition of the interfaces are presented in Figure 5. The corresponding pattern must now be added to the CAD model. Figure 12 shows tolerancing for the auxiliary reference frame of the flange, and automatically generated by Quick GPS in 30 seconds. Datum $D$ is a primary plane, and secondary datum $E$ is a cylinder perpendicular to $D$. The set of three tappings $F$ must be located with respect to datum reference frame $D \mid E$.

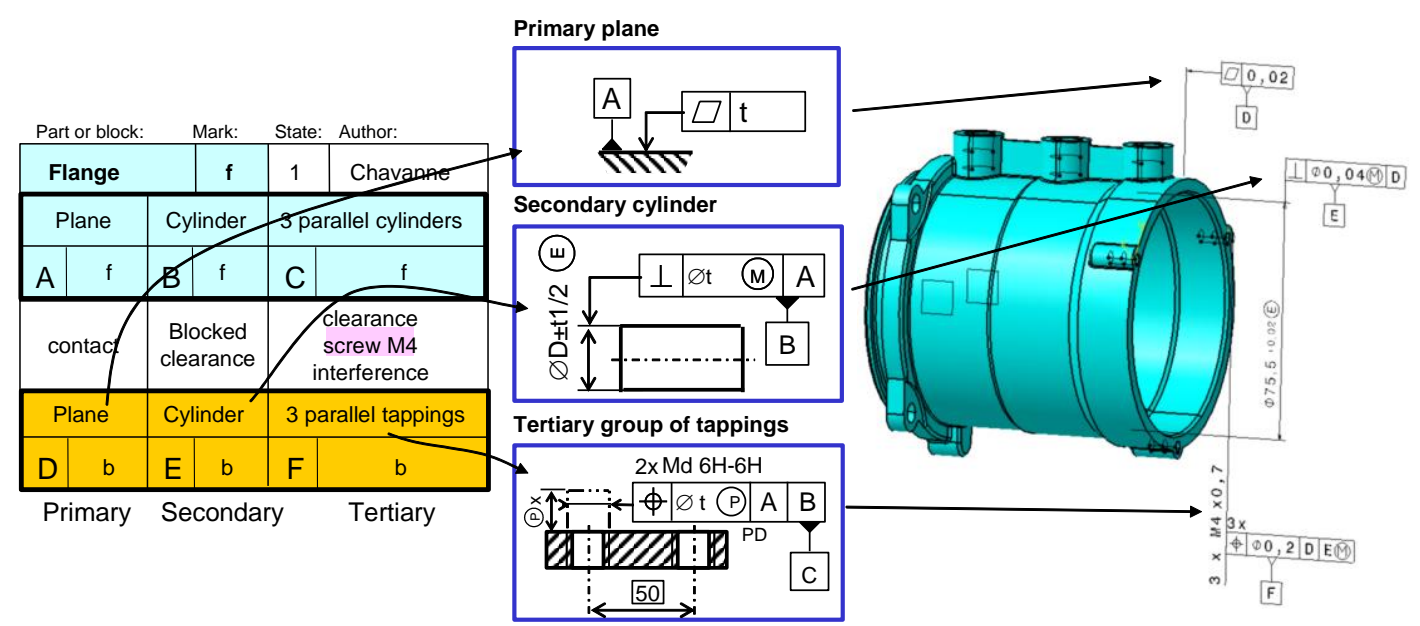

Figure 12: Creation of an auxiliary reference frame for the flange

\subsection{Rule 2: Specification determination}

In Figure 11, some patterns for secondary and tertiary planes or cylinders suggest one of two solutions: orientation or position for any feature. Most of these cases require the orientation specification, yet the position specification must be applied if a dimension must be defined between the toleranced surface and a datum, e.g. if the feature is parallel to a datum.

To formalize the choice decision, TTRS theory is used to identify all possible cases, but with more details in order to determine the symbol and if the tolerance zone is cylindrical $(\varnothing)$ or not. Figure 13 sets forth the specifications to be applied to these features, depending on whether the toleranced surface and datum system. This datum system belongs to one class among: planar, cylindrical, prismatic, revolution, spherical and complex.

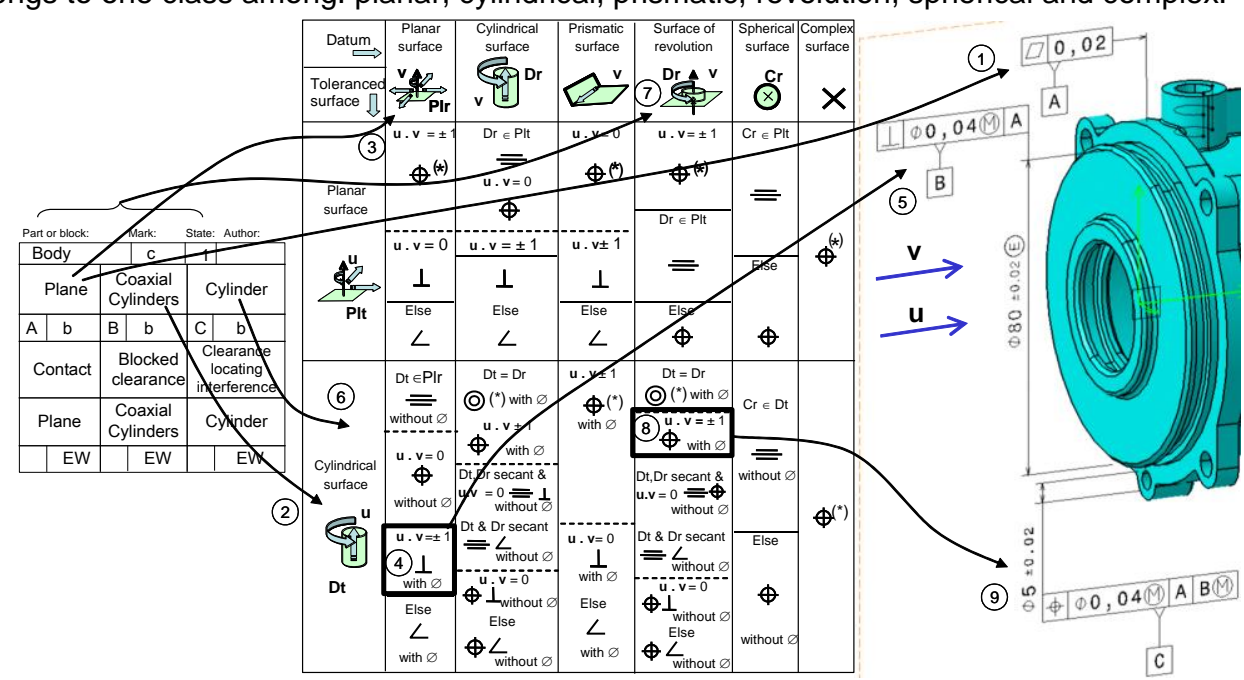

Figure 13: Specifications according to the types of toleranced surfaces and datum system

Figure 13 displays the tolerancing of main reference frame of the body starting from its positioning table.

The primary surface is plane A. Figure 11 suggests a simple type of flatness (1).

The secondary feature is composed of two coaxial cylinders of direction $\mathbf{u}$ (2). The primary datum is a plane normal to $\mathbf{v}$ (3). For both a planar reference surface and a cylindrical toleranced surface, the test (4) $\mathbf{u} . \mathbf{v}= \pm 1$ is true. The specification is perpendicularity with the $\varnothing$ symbol (5). 
The tertiary feature is a simple cylinder of direction $\mathbf{u}(6$. The datum system $A \mid B$ belongs to a revolution class with the $\mathbf{v}$ axis (7). The test (8) $\mathbf{u} . \mathbf{v}= \pm 1$ is true. The specification is a location with the $\varnothing$ symbol.

The table in figure 13 is intended to control the positioning table. The reclassification result for both toleranced surface and datum should not be in the same class as the datum. A star indicates that this case is impossible for positioning specifications (but usable for the other requirements described in Section 4).

\subsection{Rule 3: Maximum material modifier}

The clearance is obviously favorable for the mechanism assembly. The maximum material modifier should be introduced on both a toleranced surface and a datum surface, provided the availability of clearance at the corresponding interface (Fig. 14).

Theoretically speaking, this rule can be applied to all surfaces. At the present time, ISO standards do not accept this modifier for a free form surface with profile specification. Figure 14 depicts a shaft composed of three free surfaces. Quick GPS displays a comment "MMC only" that merely states the given boundary under the maximum material condition. ASME Y14.5-2009 accepts this modifier with this type of profiles.
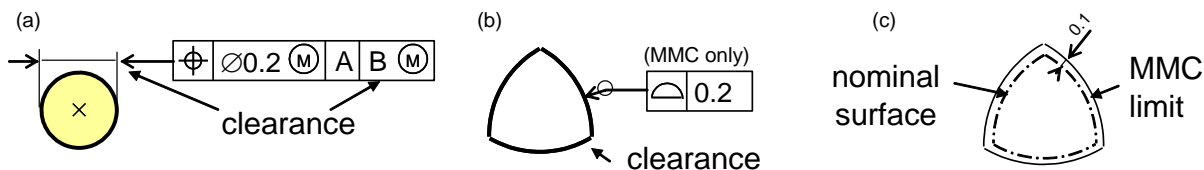

Figure 14: Clearance on both a cylinder and free surface

\subsection{Rule 4: Split set-up}

In the simple case shown in Figure 5, the flange is set up on just one part: the body. The auxiliary datum reference frame can be completely defined on the body.

If one positioning feature is split on different parts, the problem can be solved with CLIC approach.

The primary positioning feature of the shaft is made of surfaces $1 \mathrm{~s}, 2 \mathrm{~s}$ and $3 \mathrm{~s}$ (Fig. 15). $1 \mathrm{~s}$ is fitted to the body. $2 \mathrm{~s}$ and $3 \mathrm{~s}$ are fitted to the flange. According to Figure 11, the first step of the CLIC method proposes a straightness specification on both subsets defined by the positioning graph, the shaft and the body block.

(a) Body block
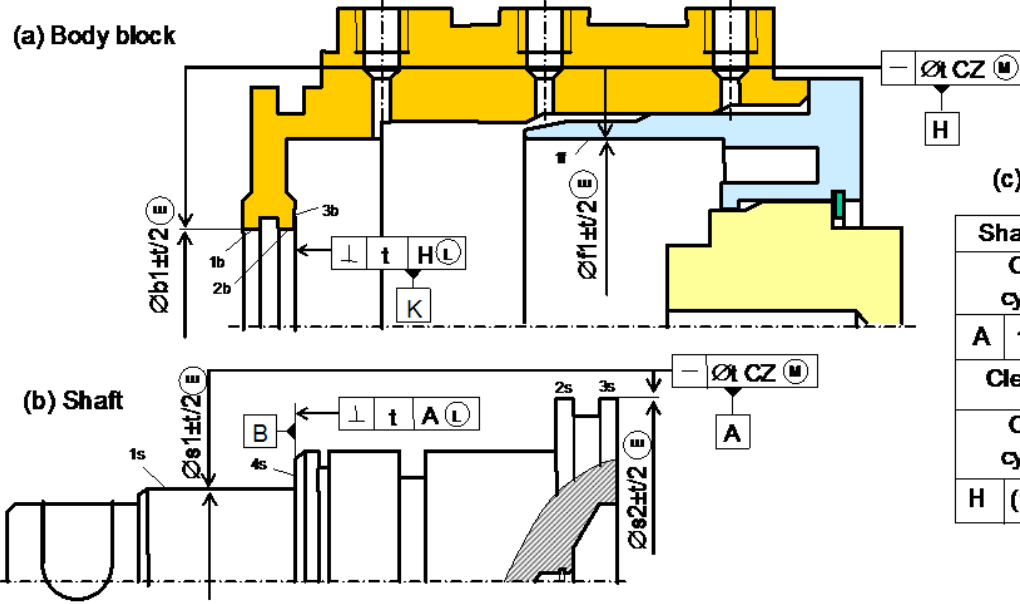

(c)

\begin{tabular}{|c|c|c|c|}
\hline \multirow{2}{*}{\multicolumn{2}{|c|}{$\begin{array}{c}\text { Shaft } \\
\begin{array}{c}\text { Coaxial } \\
\text { cylinders }\end{array}\end{array}$}} & $\mathbf{s}$ & \\
\hline & & \multicolumn{2}{|c|}{ Plane } \\
\hline A & $1 s,(2 s, 3 s)$ & B & 4s \\
\hline \multicolumn{2}{|c|}{ Clearance } & \multicolumn{2}{|c|}{ Contact } \\
\hline \multicolumn{2}{|c|}{$\begin{array}{l}\text { Coaxial } \\
\text { cylinders }\end{array}$} & \multicolumn{2}{|c|}{ Plane } \\
\hline H & $(1 b, 2 b), 1 f$ & K & $\mathbf{3 b}$ \\
\hline
\end{tabular}

Figure 15: Straightness of both body block and shaft

The tolerancing of the body block is currently defined between different parts and requires a second step. The flange positioning table (Fig. 4) reveals that the flange is set up on the body.

With CLIC method, a specification in common zone must be broken down into both location and orientation of each surface with respect to a common datum reference frame.

The straightness therefore is broken down into location and orientation specifications of body surfaces $(1 \mathrm{~b}, 2 \mathrm{~b})$ and flange surface 1f, with respect to the datum reference systems defined on the junction between flange and body (Fig. 16). The clearance between flange and body imposes an LMC modifier on the datum reference frame. 

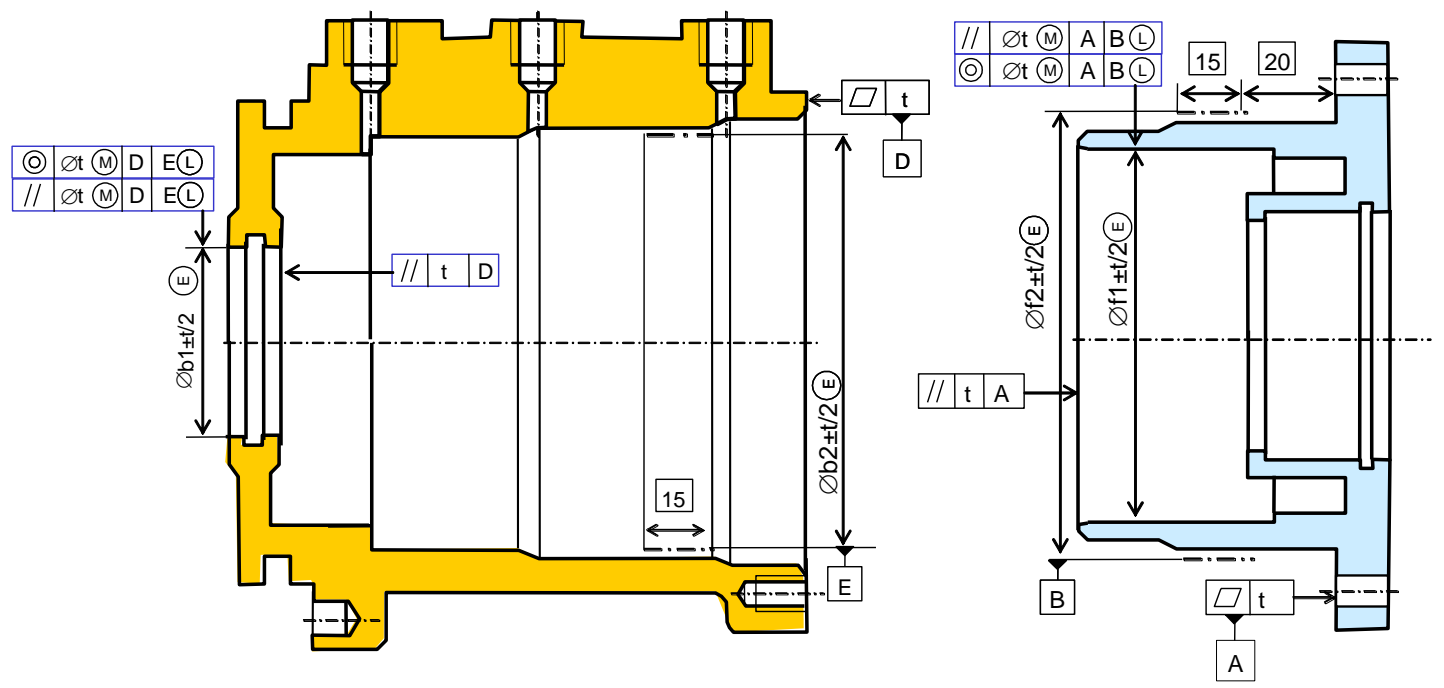

Figure 16: Breakdown of straightness into locations and orientations

In this case, by using Quick GPS, during the interactive definition of the primary auxiliary positioning features of the body, the designer is only able to select the two body cylinders (1b,2b) (Fig 15) and must notify in a dialog box that this feature is incomplete. In addition, the designer must indicate the name of the reference frame link to the other surfaces of the shaft positioning feature. Also in this case, the datum reference frame to be used is the auxiliary frame $D \mid E$ named $A 1 f$, corresponding to the flange.

Rule 4: if all surfaces of one positioning feature do not belong to the active part, surfaces of active part must be located and oriented with respect to the designed reference frame corresponding to the other surfaces.

\subsection{Results}

Figure 17 presents body specification results for the positioning requirements. Tolerance values are, by default, set at basic values, e.g. defined at 0.02 for flatness, and must be adjusted by the designer.

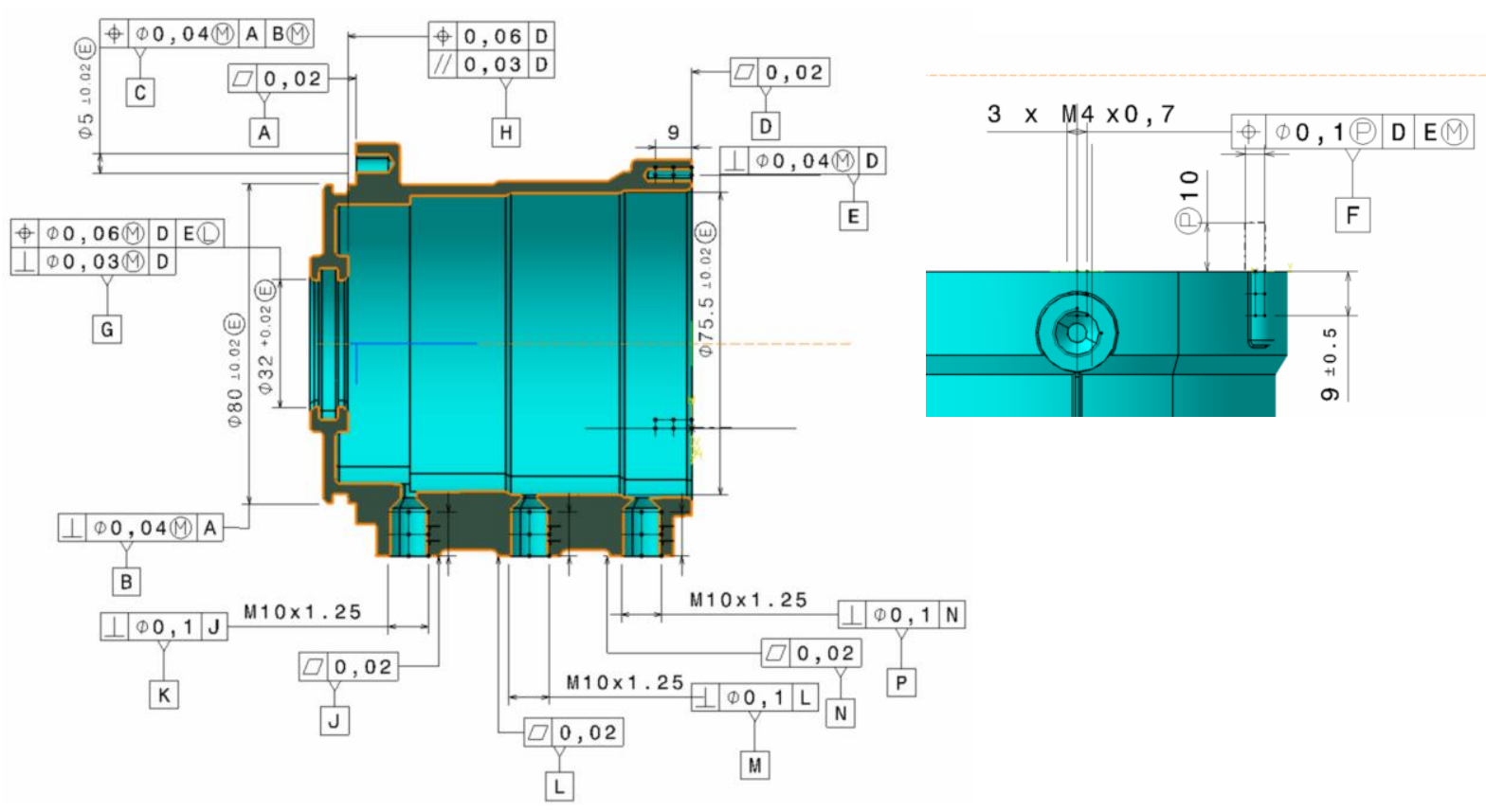

Figure 17: Results for the positioning requirement specifications

$\mathrm{A}|\mathrm{B}| \mathrm{C}$ represents the main reference frame $(\mathrm{R} 1 \mathrm{~b})$ of the body defined in the body positioning table (Fig. 12).

$\mathrm{D}|\mathrm{E}| \mathrm{F}$ constitutes the auxiliary reference frame for the flange, denoted A1f according to the flange positioning table (Fig. 4).

$G$ represents a portion of the primary auxiliary datum of the shaft, denoted A1s (in Fig. 14), and requires both orientation and location specifications with respect to the auxiliary reference frame $D \mid E$ of the flange.

The pairs $(J, K),(L, M)$ and $(N, P)$ correspond to the auxiliary reference frames of nipples $(A 1 n, A 2 n, A 3 n)$. 


\section{RELATIVE POSITION OF REFERENCE FRAMES}

\subsection{Links between reference frames}

In the CLIC method, the synthesis of specifications is based on a set of functional requirements between functional surfaces. For each functional requirement, the contact loop links functional surfaces, thus allowing for the generating of functional specifications on influent surfaces as well as for the relationship between tolerances for these specifications [11]. In this manner, the 3D tolerancing chain creates links between the various datum reference frames of each part.

According to the Quick GPS approach, the designer must indicates the set of useful links between the various datum reference frames (R1b, A1f, A1s, A1n, A2n and A3n) created in Section 3.7 (Fig. 18).
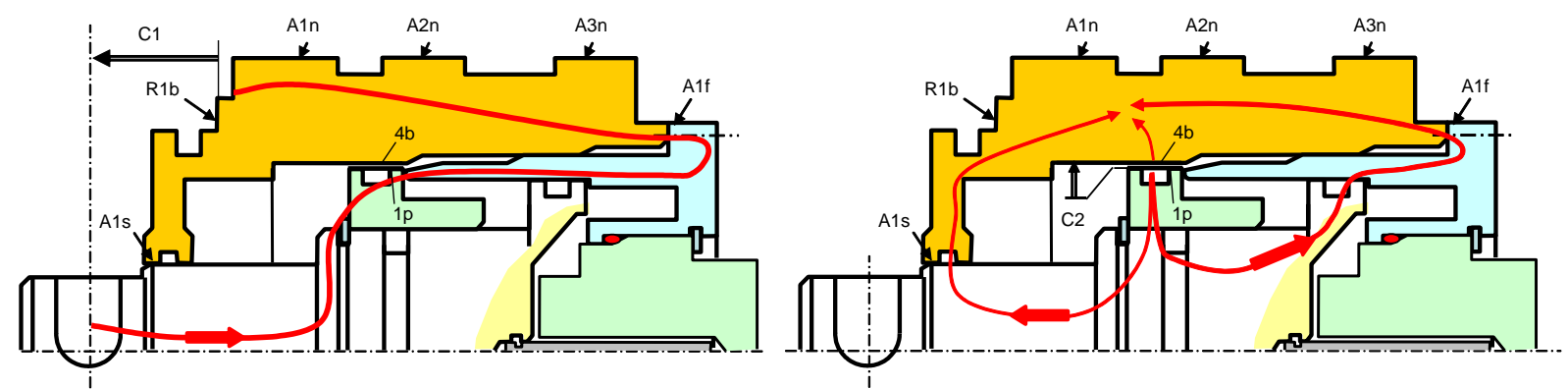

Figure 18: Search for links

In a basic approach, the designer would identify all mechanism requirements and determine the contact loop that links functional surfaces. This loop serves to link the influential reference frames of each part. As an example, in figure 18, requirement $\mathrm{C} 1$ imposes positioning the auxiliary reference frame A1f with respect to the main reference frame $\mathrm{R} 1 \mathrm{~b}$. $\mathrm{C} 2$ requires a minimum distance between the piston and surface $4 \mathrm{~b}$ of the body, which in turn imposes a link between A1s, A1f and functional surfaces $4 \mathrm{~b}$.

This method is still not very efficient due to the difficulty involved in identifying all mechanism requirements. Furthermore, many contact loops do not relate to the active part, and a considerable number of these loops actually link the same reference frames.

\subsection{Specification corresponding to links}

This second method is more efficient. The designer must analyze the influence of the displacement of each auxiliary datum reference frame, which directly yields the other target frames and allows detecting the functional surfaces of the active part. For example, if the hole of datum reference frame A1s is placed too high, interference will arise between the piston and surface $4 b$ of the body. The displacement of A1f exerts the same effect, hence A1s and A1f must display a good relative position.

Figure 19 depicts the various links considered useful for this body.

- Datum reference frames A1f, A1s must be located with respect to main frame R1.

- Surfaces $13 \mathrm{~b}$ and $14 \mathrm{~b}$ (corresponding to interference with the piston) must be located with respect to A1f.

- Set of holes (fixture of the body) must be located with respect to R1.

This example offers a complementary approach: three nipples are fixed in three tappings. To avoid interference between nipples, a minimal distance is required between tappings. In this case, the Quick GPS method proposes grouping these positioning features $A 1 n, A 2 n$ and $A 3 n$ into a single group $\mathrm{G} 1$, which is then located with respect to main frame $\mathrm{R} 1$.

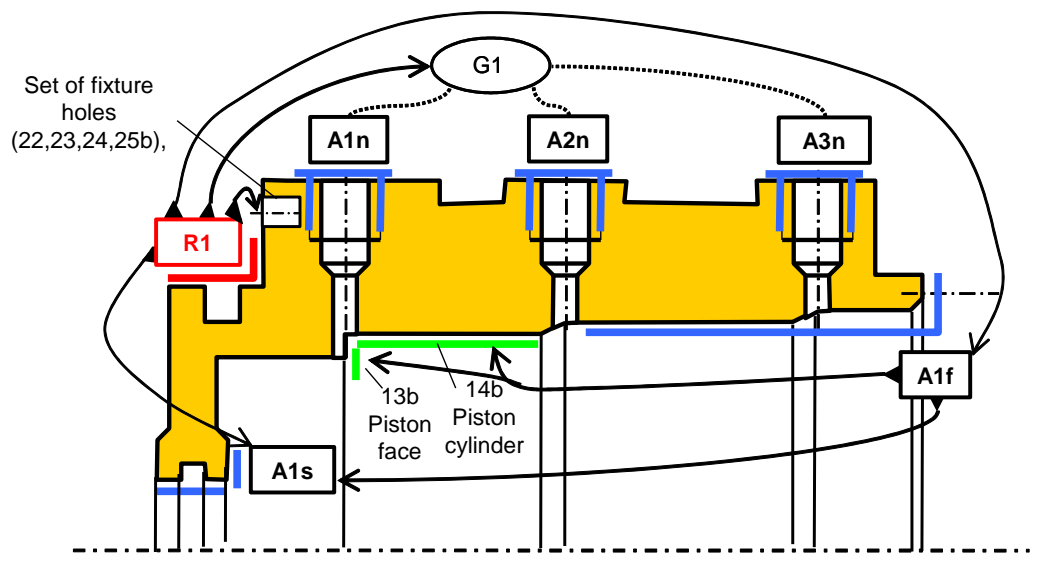


A simple dialog box allows creating group $G 1$, which provides the set of frames $A 1 n, A 2 n, A 3 n$.

The third phase displays the matrix (see Table 1), which contains all frames, all isolated functional surfaces, all groups and a single specific column for general tolerancing. The cells shown in gray on this table are impossible to obtain and therefore locked. The designer must now place the letter "P" in order to localize a frame or functional surface with respect to a given datum reference frame. The letter " $\mathrm{O}$ " indicates an orientation specification and $\mathrm{F}$ for a form specification.

\begin{tabular}{|c|c|c|c|c|c|c|c|c|c|c|c|}
\hline \begin{tabular}{|l} 
Reference \\
frames
\end{tabular} & R1 $(A, B, C)$ & A1f $(D, E, F)$ & A1s (G,H) & A1n $(\mathrm{J}, \mathrm{K})$ & A2n (L,M) & A3n $(N, P)$ & G1 & $\begin{array}{l}\text { Piston } \\
\text { cylinder;CY } \\
\mathrm{S}: 13\end{array}$ & $\begin{array}{l}\text { Piston } \\
\text { face;PLS : } \\
14\end{array}$ & $\begin{array}{l}\text { General } \\
\text { tolerancing } \\
15\end{array}$ & $\begin{array}{l}\text { Set of fixture } \\
\text { holes; CYG : } \\
22,23,24,25\end{array}$ \\
\hline R1 & & $\mathrm{P}$ & $\mathrm{P}$ & & & & $\mathrm{P}$ & & & $\mathrm{P}$ & $\mathrm{P}$ \\
\hline A1f & & & $\mathrm{P}$ & & & & & $\mathrm{P}$ & $\mathrm{P}$ & & \\
\hline \multicolumn{12}{|l|}{$\mathrm{A} 1 \# \mathrm{ba}$} \\
\hline A1n & & & & & G1 & G1 & & & & & \\
\hline A2n & & & & G1 & & G1 & & & & & \\
\hline$A 3 n$ & & & & G1 & G1 & & & & & & \\
\hline G1 & & & & & & & & & & & \\
\hline
\end{tabular}

Table 1: Relative position between datum reference frames

\subsection{Tolerancing rules}

The next phase generates the tolerancing corresponding to these links.

Rule 5: For each link displayed in Table 1, all surfaces of the specified frame must be located or oriented with respect to the reference frame.

Rule 6: For each specification, the algorithm summarized in Figure 20 enables determining whether one, two or three references are needed.

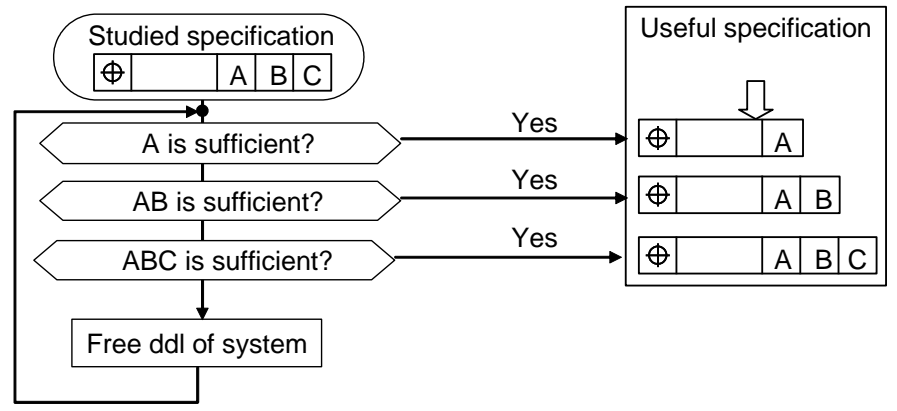

Figure 20: Test of datum frame combinations

Table 2 describes in detail the condition employed in figure 20 to determine whether the reference frame is indeed sufficient for a given position specification. A similar table exists for the orientation specifications. This frame is associated with a TTRS to be calculated by means of reclassification [23]. 


\begin{tabular}{|c|c|c|c|c|c|c|}
\hline$\underset{\begin{array}{c}\text { Datum } \\
\text { soleranced } \\
\text { surface }\end{array}}{\longrightarrow}$ & $\begin{array}{l}\text { Planar } \\
\text { surface }\end{array}$ & $\begin{array}{l}\text { Cylindrical } \\
\text { surface }\end{array}$ & $\begin{array}{c}\text { Prismatic } \\
\text { surface }\end{array}$ & $\begin{array}{l}\text { Surface of } \\
\text { revolution }\end{array}$ & $\begin{array}{c}\begin{array}{c}\text { Spherical } \\
\text { surface }\end{array} \\
\otimes\end{array}$ & $\begin{array}{c}\text { Complex } \\
\text { surface } \\
X\end{array}$ \\
\hline $\begin{array}{c}\text { Planar } \\
\text { surface }\end{array}$ & $\mathbf{u}= \pm \mathbf{v}$ & No & $\mathbf{u} \cdot \mathbf{v}=0$ & $\mathbf{u}= \pm \mathbf{v}$ & No & Yes \\
\hline $\begin{array}{l}\text { Cylindrical } \\
\text { surface } \\
\text { D }\end{array}$ & No & $\begin{array}{c}\mathbf{u}= \pm \mathbf{v} \\
\text { and } D=\Delta\end{array}$ & $\mathbf{u}= \pm \mathbf{v}$ & $\begin{array}{c}\mathbf{u}= \pm \mathbf{v} \\
\text { and } \mathrm{D}=\Delta\end{array}$ & No & Yes \\
\hline $\begin{array}{l}\text { Prismatic } \\
\text { surface }\end{array}$ & No & No & $\mathbf{u}= \pm \mathbf{v}$ & No & No & Yes \\
\hline $\begin{array}{l}\text { Surface of } \\
\text { revolution }\end{array}$ & No & No & No & $\begin{array}{c}\mathbf{u}= \pm \mathbf{v} \\
\text { and } \mathrm{D}=\Delta\end{array}$ & No & Yes \\
\hline $\begin{array}{l}\text { Spherical } \\
\text { surface } \\
\bigotimes\end{array}$ & No & No & No & $\mathrm{F} \in \Delta$ & $F=0$ & Yes \\
\hline $\begin{array}{c}\text { Complex } \\
\text { surface } \\
X\end{array}$ & No & No & No & No & No & Yes \\
\hline
\end{tabular}

Table 2: Datum system test for positioning

Rule 7: The choice of specification symbol respects Figure 13.

Rule 8: If the toleranced surface or datum is a fitting feature with clearance, it becomes necessary to add a minimum material modifier.

In choosing the positioning surface specification, Maeda [24] proposed a model to express the behavior of a toleranced feature by using the degree of freedom for this feature. TTRS theory is used to model surface associations and then, based on these associations, proposes standardized tolerancing [22]. O.W. Salomons applied the same method with minor changes [10]. 


\subsection{Results}

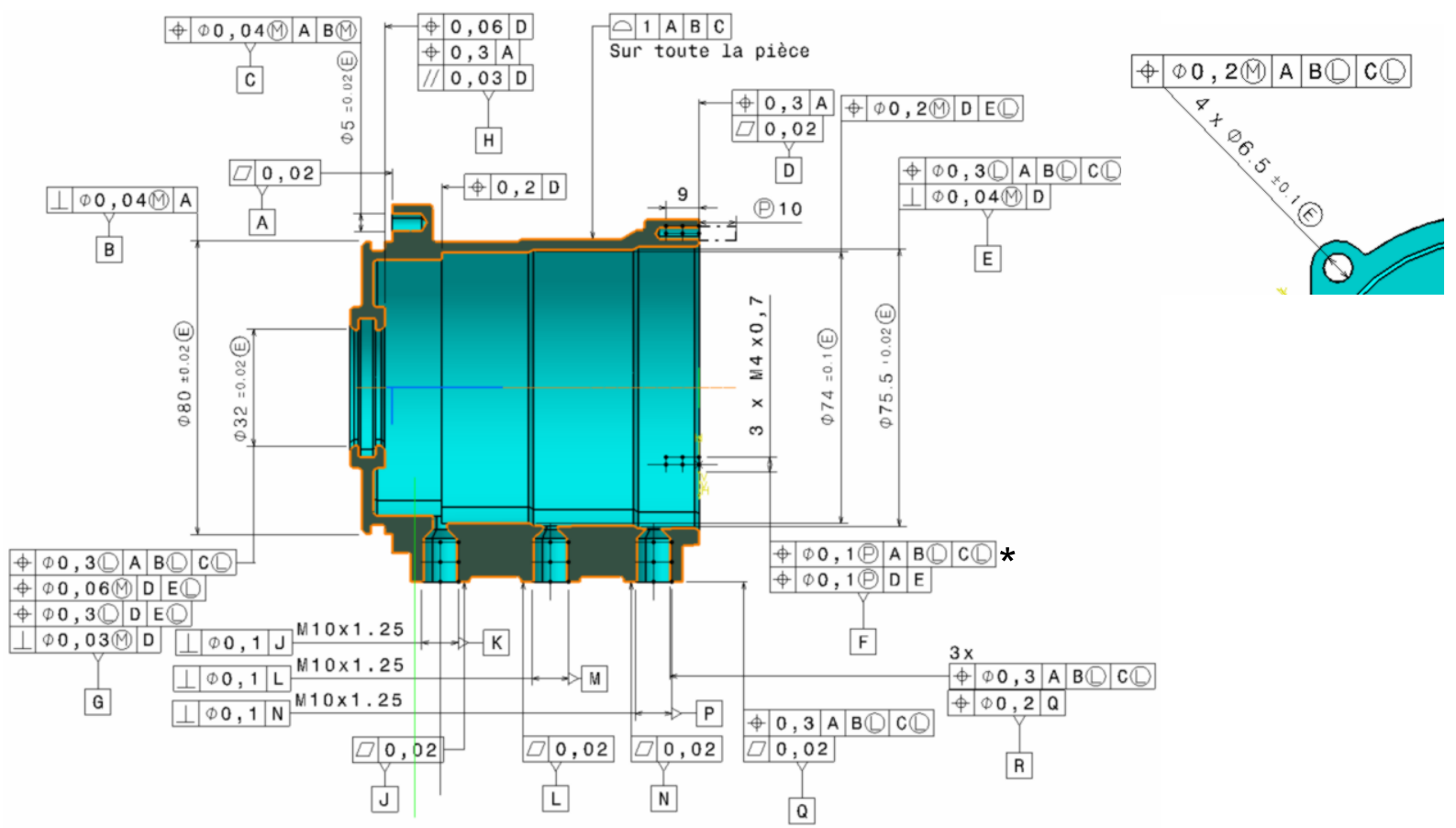

Figure 21: Complete tolerancing based on Quick GPS

Figure 21 indicates the complete tolerancing, including locations and orientations obtained by the links defined in Table 1.

The grouping of the three tappings allows for just one location specification of the planes (datum $Q$ ) in the common zone and one location of the group of tappings (datum R); otherwise, without any such grouping, six independent specifications would be created.

This tolerancing may be excessive. For example, the location of the group of three tappings (denoted with a star in Fig. 21) proves useless. However, such a location step would have been necessary if a hole in the flange had been positioned in front of a hole of the body in order to pass air through the flange. The designer must therefore analyze the relevance of the proposed specifications and possibly delete some of them. Experience demonstrates that this case is quite rare.

\section{IMPLEMENTATION OF QUICK GPS}

\subsection{General structure}

Tolerancing annotations are created using the functional tolerancing and annotations (FT\&A) workbench of CATIA V5. The Quick GPS tolerancing method has been implemented within a CATIA VBA environment (Dassault Systèmes), with data stored in a simple Excel spreadsheet. The application comprises 3 steps (Fig. 22). The first step enables an interactive dialogue between the designer and the computer-aided tool. For each link with the neighboring parts, the designer selects the primary, secondary and tertiary positioning features through the use of the CATIA interface. The designer must also select isolated functional surfaces. Surface characteristics are stored in the Excel spreadsheets as well.

During the second step, VBA procedures generate tolerancing data in accordance with the previous set of tolerancing rules (Fig. 22). Each specification listed in an Excel spreadsheet can be modified or deleted, and tolerances can be adjusted.

Finally in step 3, all ISO functional specifications are transferred into the CAD model with a CAA procedure, by means of the FT\&A semantic language. Views and captures are created automatically. 

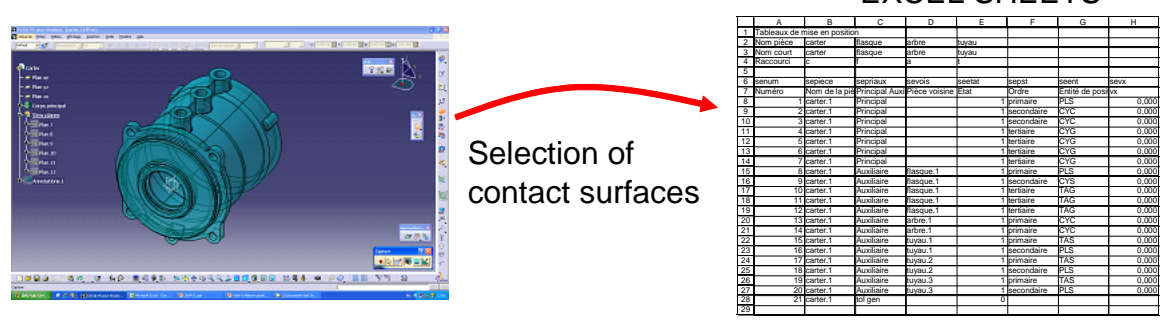

Generation of
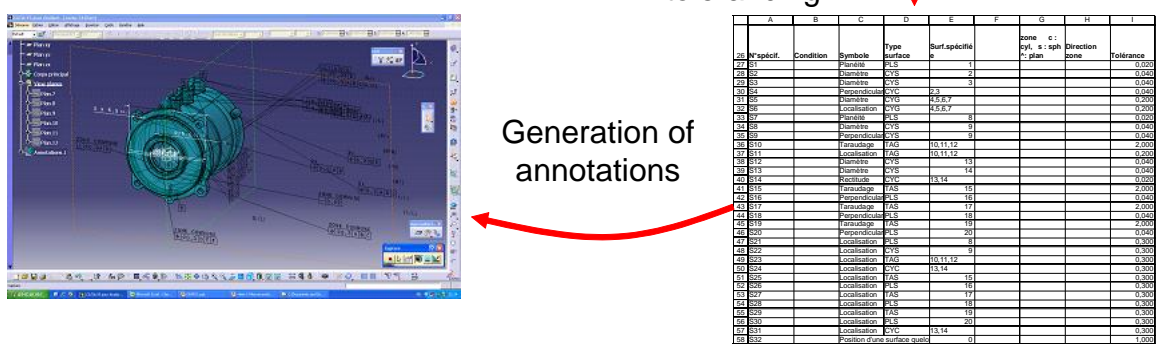

Figure 22: Interface with the CAD system

\subsection{Comments}

Each specification is described in an Excel spreadsheet, including comments to explain the specification and/or function performed by the specification or possible failure should the specification not be respected.

\begin{tabular}{|c|c|c|c|l|c|c|l|l|}
\hline \#specif & Symbole & $\begin{array}{l}\text { Type of } \\
\text { surface }\end{array}$ & $\begin{array}{c}\text { Specified } \\
\text { surface }\end{array}$ & $\begin{array}{l}\text { cone } \mathbf{s}: \mathbf{s p h} \\
\wedge: \text { plane }\end{array}$ & Tolerance & Modifier & $\begin{array}{l}\text { Reference } \\
\text { frame }\end{array}$ & Comment \\
\hline S1 & Flatness & PLS & 1 & & 0.02 & & & $\begin{array}{l}\text { Flatness of primary plane to guarantee a good contact of main } \\
\text { datum system }\end{array}$ \\
\hline S2 & Diameter & CYS & 2 & & 0.04 & & & $\begin{array}{l}\text { Diameter with envelop requirement to guarantee the assembly of } \\
\text { secondary surface of main datum system }\end{array}$ \\
\hline S3 & Diameter & CYS & 3 & & 0.04 & & & $\begin{array}{l}\text { Diameter with envelop requirement to guarantee the assembly of } \\
\text { secondary surface of main datum system }\end{array}$ \\
\hline S4 & Perpendicularity & CYC & 2,3 & C & 0.04 & $\mathrm{M}$ & $\mathrm{A}$ & $\begin{array}{l}\text { Perpendicularity at maximum material condition to guarantee the } \\
\text { assembly of main datum system }\end{array}$ \\
\hline S5 & Diameter & CYS & 4 & & 0.04 & & & $\begin{array}{l}\text { Diameter with envelop requirement to guarantee the assembly of } \\
\text { tertiary surface of main datum system }\end{array}$ \\
\hline S6 & Location & CYS & 4 & & 0.04 & $\mathrm{M}$ & $\mathrm{A} \mid \mathrm{B}(\mathrm{M})$ & $\begin{array}{l}\text { Location of tertiary surface with regard to primary and secondary } \\
\text { datum to guarantee the assembly of main datum system }\end{array}$ \\
\hline
\end{tabular}

Table 3: Comments table

\subsection{Creation of annotations in the 3D CAD model with a CAA procedure}

The main development introduced in this part is based on the CATIA V5 Component Application Architecture (CAA). A CAA application is composed of references to functions available in the API libraries and contained in different CATIA V5 components.

In CAA V5, the CATTPSInterfaces framework provides interfaces to describe the Technological Product Specification (TPS) domain; moreover, the CATTTRSInterfaces framework provides interfaces to link TPS with surfaces. The object model of tolerancing components is represented in Table 3, with each TPS object adhering to various interfaces, which define the set of specific behavior that the object is required to support. As an example, for a given annotation set object, the CATITPSSet interface allows retrieving standards and the TPS components included in this set, while the CATITPSFactoryElementary interface provides the basic factory for annotation creation. The client application focuses on the object solely through the interface.

A new CAA procedure has been developed and integrated into the FT\&A (Functional Tolerancing \& Annotation) workbench of CATIA (Figure 23). Tolerancing data are retrieved from an Excel spreadsheet using straight $\mathrm{C}_{++}$ automation code. User surfaces and group of user surfaces (TTRS) are created on topological cells that correspond to the stored generic naming labels, with all ISO functional specifications then being generated in the following strict order:

- Creation of datums

- Creation of datum reference frames

- Creation of semantic dimensions and geometric tolerances. 
With a number of interfaces implemented by a single annotation object, each annotation can be characterized by various parameters, such as: dimension limits (CATITPSDimensionLimits), tolerance zone form (CATITPSToleranceZone), envelop condition modifier (CATITPSEnvelopCondition), and material condition modifier on the tolerance or datum reference frame (CATITPSMaterialCondition).

A view plane is created for several annotations. The following rules should be respected for each annotation:

- A specification concerning a cylinder or coaxial cylinders requires a cross-section view plane passing through the axis (diameter, coaxiality, location, etc.);

- A specification concerning a plane requires a view plane perpendicular to the toleranced plane (flatness, location, etc.);

- A specification concerning a set of holes requires a front view plane perpendicular to the axis of the holes.

This procedure will create a minimum number of view planes and set each annotation into a single view plane, which is also helpful for creating a generative drawing sheet.

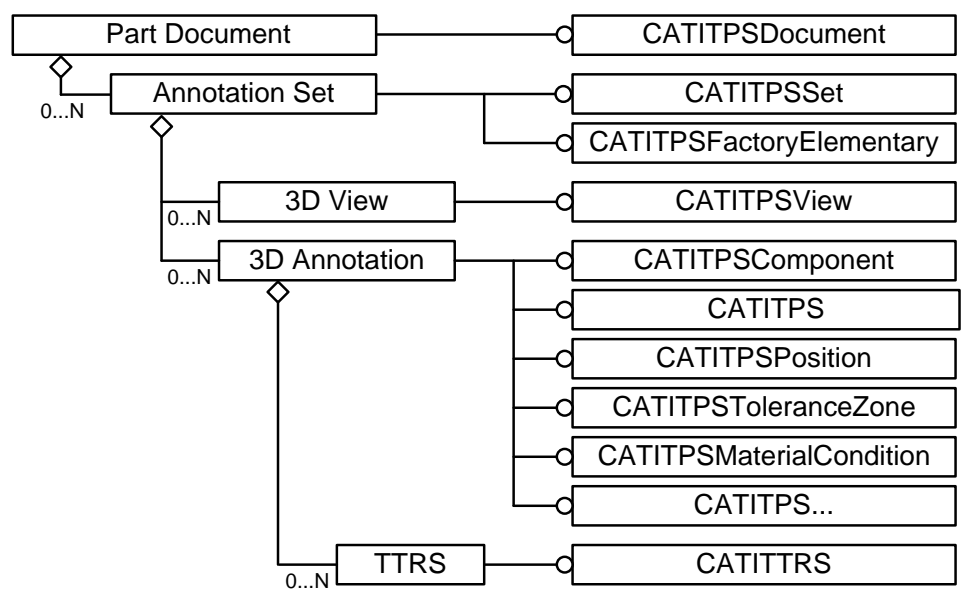

Figure 23: The object model of tolerancing components [5]

\subsection{Grouping of annotations}

The previous procedure merely creates isolated annotations. For a master 3D annotation, the following slave 3D annotations, regarding the same surface or set of surfaces, can be grouped under this annotation through the CATITPSAssociativeGroup interface. Another CAA procedure has been developed to automatically group all annotations in order to offer a clear presentation. Final tolerancing results are shown in Figure 21.

\subsection{Limitations}

Due to the principle behind Quick GPS, this software only recognizes one part. It is impossible therefore to manage the tolerances and lengths of projected zones. Restricted zones corresponding to the surface actually in contact between two parts cannot be delimited, leading to confusion if two different parts are in contact with the same face, e.g. the left face of the piston in contact with both the circlips and the body in the central configuration.

The tolerancing generated by current rule 3 is not guaranteed if the set-up of one part is provided by more than two parts, since it is impossible to analyze the degrees of freedom blocked by an unknown part.

Free surfaces are considered as complex surfaces with six degrees of freedom blocked. This point is currently under development.

The tolerancing is still incomplete, as regards for example growing, tapping and pinion. The proposed tolerancing is limited to assembly requirements and links between reference frames.

The current CAA V5 development tools available in CATIA V5 are very complex for programming applications. Due to the limitation of APIs, the CAA procedures developed remain limited, for example, for framed basic dimension and projected zone.

\section{CONCLUSION}

This paper has demonstrated that a consistent tolerancing of a single part may be achieved with knowledge of both the positioning tables and the links between the various contact surfaces. The Quick GPS method provides an efficient solution for many industries, in cases where each designer is responsible for just a single part. The positioning table offers a way to specify all joints so as to respect positioning requirements. The table summarizes all links into the part and then serves as an alternative to the classical 3D chain transfer approach for the contextual study of a single part. 
This method has now been implemented within a VBA environment, in interaction with the CATIA environment. The module has proven to be very effective: the selection of set-up surfaces takes just 5 minutes, and body tolerancing generates 42 specifications in only 20 seconds. As opposed to Armillotta's findings [21], the contact surfaces are not detected automatically, yet the subsequent goal of this application is to enhance the assembly method on a CAD model by integrating the positioning table concept.

This approach is not sufficient for tolerance optimization, a process that requires tolerance chains and a system of complex equations. This is still open to investigate using other commercial software, such as 3DCS and MECAmaster, in order to determine the effect of these tolerances on functional characteristics.

Finally, one major advantage of the work presented here is the introduction of junction analysis between parts within the designer methodology.

\section{REFERENCES}

[1] ISO/TR 14638:1995, Geometrical product specification (GPS) - Masterplan

[2] ISO/TC213, 2002, ISO/TC213; "ISO/TS 17450-2: Geometrical Product Specifications (GPS) --General Concepts--Part 2: Basic tenets, specifications, operators and Uncertainties"; 2002; Geneva.

[3] V. Srinivasan, An Integrated View of Geometrical Product Specification and verification, Proceedings $7^{\text {th }} \mathrm{CIRP}$ CAT Seminar, Cachan, France, 2001

[4] W. Lu, X. Jiang, P.J. Scott, X. Lan A Host System for Form Tolerance Specification in the Next-generation GPS based on AutoCAD, Proceeding $11^{\text {th }}$ CIRP CAT seminar, Annecy, France, 2009

[5] CAA V5 Encyclopedia 2007, Dassault Systèmes. http ://www.3ds.com

[6] D. Gaunet, 3D Functional Tolerancing \& Annotation: CATIA tools for Geometrical Product Specification, Geometric Product Specification, Kluwer, 2003, pp25-33

[7] P. Clozel, 3D tolerance analysis, from preliminary study, Geometric Product Specification, Kluwer, 2003, pp 93-104

[8] C. Therrien, DimXpert for parts: Introduction for Resellers, SolidWorks. http://www.solidworks.com/

[9] 0.W. Salomons, F.J. Haalboom, H.J. Jonge Poerink, F. van Sloten, F.J.A.M. van Houten, H.J.J. Kals, A computer aided tolerancing tool II:Tolerance analysis, Computer In industry, 31 (1996), 161-174

[10] 0.W. Salomons, F.J. Haalboom, H.J. Jonge Poerink, F. van Sloten, F.J.A.M. van Houten, H.J.J. Kals, A computer aided tolerancing tool II:Tolerance analysis, Computer In industry, 31 (1996), 175-186

[11] B. Anselmetti, Generation of functional tolerancing based on positioning features, Computer-Aided Design, 38 (2006) 902-919.

[12] B. Anselmetti, Bases de la cotation fonctionnelle, Vol 2, Lavoisier, 2008

[13] B. Anselmetti, Cotation fonctionnelle tridimensionnelle et statistique, Vol 3, Lavoisier, 2008

[14] B. Anselmetti, Part optimization and tolerances synthesis, Int J Adv Manuf Technol, doi 10.1007/s001 70009-2355-6, (2009)

[15] B. Anselmetti, K. Mawussi, Computer Aided Tolerancing using Positioning Feature, J. of Computing and Information Science in Engineering, 3/15 (2003) 15-21

[16] J-M. Linarès, C. Marty, Tolerancing by functional group, Proceedings $3^{\text {rd }}$ CIRP CAT Seminar, Cachan, France (1993), 267-277.

[17] A. Ballu, L. Mathieu, Choice of functional specifications using graphs within the framework of education, Integrated Design and Manufacturing in Mechanical Engineering, KLUWER, 1999, pp. 197-206

[18] D. Teissendier, Y. Couetard, A. Gerard, Three-dimensional functional tolerancing with proportional assembly clearance volume (UPEL): Application to setup planning, Proceedings $5^{\text {th }}$ CIRP CAT Seminar, Toronto, Canada, (1997), 113-123.

[19] S. Samper, M. Giordano, Models for tolerancing process by considering mechanism flexibility, Integrated Design and Manufacturing in Mechanical Engineering, KLUWER Academic Publishers (1996), pp. 349-356.

[20] B. Marguet, L. Mathieu, Method for Geometric Variation Management from Key Characteristics to Specification, Proceedings $7^{\text {th }}$ CIRP CAT Seminar, Cachan, France, (2001), 217-226.

[21] A. Armillotta, Q. Semeraro, Tolerance specification through automated generation of assembly requirement, Proceedings $10^{\text {th }}$ CIRP CAT Seminar, Erlangen, Germany, (2007), 11-24

[22] A. Clement, A. Rivière, M., Temmerman, Cotation tridimensionnelle des systèmes mécaniques: Théorie et pratique, PYC Edition, France (1994).

[23] J-Y. Dantan, T. Landmann, A. Siadat, P. Martin, A System for Modeling Geometric Tolerances for Mechanical Design, Proceedings $9^{\text {th }}$ CIRP CAT Seminar, Tempe, USA (2005), 55-64.

[24] T. Maeda, D. Yonekura N. Tokuoka, A Toleranced feature modelling by constant of degree of freedom for assignment of tolerance, Proceedings $4^{\text {th }}$ CIRP CAT Seminar, Tokyo, Japan, (1995), 121-128. 